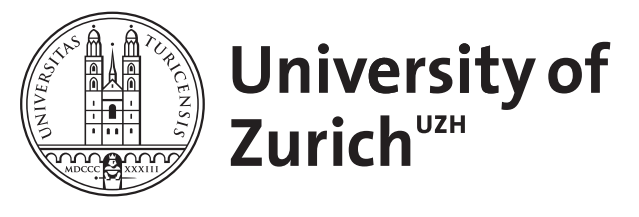

\title{
Topical therapies in inflammatory bowel disease
}

Frei, Pascal ; Biedermann, Luc ; Manser, Christine N ; Wilk, Maike ; Manz, Michael ; Vavricka, Stephan R ; Rogler, Gerhard

\begin{abstract}
Due to misunderstandings about their effectiveness and feasibility, topical (or rectal) therapies with aminosalicylates (5-aminosalicylic acid, 5-ASA) and steroids are often underused in patients with ulcerative colitis (UC). However, many of these patients could be treated solely with rectal/topical therapies, or could benefit from them in combination with oral therapies. We review the evidence for topical therapies containing 5-ASA and budesonide in UC and discuss how these therapies can be optimized in daily practice, thereby improving compliance. Finally, we provide a brief summary of studies on the use of other topical treatments in UC, the results of which were both promising and negative.
\end{abstract}

DOI: https://doi.org/10.1159/000341947

Posted at the Zurich Open Repository and Archive, University of Zurich

ZORA URL: https://doi.org/10.5167/uzh-76210

Journal Article

Accepted Version

Originally published at:

Frei, Pascal; Biedermann, Luc; Manser, Christine N; Wilk, Maike; Manz, Michael; Vavricka, Stephan R; Rogler, Gerhard (2012). Topical therapies in inflammatory bowel disease. Digestion, 86(Suppl. 1):36-44. DOI: https://doi.org/10.1159/000341947 


\section{Topical therapies in IBD}

Pascal Frei ${ }^{1}$, Luc Biedermann ${ }^{1}$, Christine Manser ${ }^{1}$, Maike Wilk ${ }^{1}$, Michael Manz ${ }^{2}$, Stephan R. Vavricka ${ }^{2}$, Gerhard Rogler ${ }^{1}$

${ }^{1}$ Division of Gastroenterology \& Hepatology, University Hospital of Zürich, Zürich, Switzerland

${ }^{2}$ Division of Gastroenterology and Hepatology, Claraspital, Basel, Switzerland

${ }^{3}$ Triemlispital Zurich, Division of Gastroenterology and Hepatology, Zurich, Switzerland

\section{Abstract}

Due to misunderstandings on their effectiveness and feasibility, topical (or rectal) therapies with aminosalicylates (5-aminosalicylic acid, 5-ASA) and steroids are often underused in patients with ulcerative colitis (UC). However, many of these patients can be treated solely with rectal/topical therapies, or can profit from combined oral and rectal/topical therapies. We review the evidence for topical therapies containing 5-ASA and budesonide in UC and discuss how topical therapies can be optimized in daily practice, thereby improving compliance. Finally, studies with both promising and negative results with other topical treatments in UC are shortly summarized.

\section{Introduction}

UC is characterized by a continuous inflammation of the colonic mucosa starting from the rectum. Extent of the disease can vary from proctitis to left sided colitis and extensive colitis or pancolitis. In most patients, only the distal colon is affected ${ }^{[1-3]} \cdot 50-60 \%$ of patients have a proctosigmoiditis, $20-30 \%$ a left-sided colitis up to the splenic flexure, and only $20 \%$ have an extensive or pancolitis. This distribution and the mucosal inflammation allow the use topical therapies with a good clinical response or even remission in most of UC patients. Topical therapies containing budesonide and 5-ASA can be used both for induction and maintenance of remission. 
Topical therapies can be applied by suppositories for the rectum in case of proctitis and by enemas (liquid) or foam preparations in case of proctosigmoiditis and left sided colitis. The distribution of topical therapies has been studied by $\gamma$-scintigraphy showing a distribution of enemas up to and sometimes even further than the splenic flexure ${ }^{[4,5]}$. Foams seem to distribute more continuously in the rectum and sigma, but they probably do not reach as far as liquid enemas ${ }^{[6]}$.

\section{Induction of remission by topical therapy}

In mild to moderate UC, aminosalicylates are first line drugs to be used according to evidence based guidelines.

Ulcerative proctitis is best treated first line with 5-ASA suppositories ${ }^{[7]}$ which target the rectal mucosa better than foams or enemas ${ }^{[8]}$. However, all topical 5-ASA formulations are equally efficacious in the treatment of proctitis $^{[9]}$. Suppositories with $1000 \mathrm{mg}$ 5-ASA are effective and seem the most feasible topical therapy ${ }^{[7,10-12]}$. Suppositories can induce remission in about two third of patients with ulcerative proctitis ${ }^{[13]}$. A meta-analysis of 11 studies showed that topical 5-ASA induces remission in $67 \%$ in contrast to only $7-11 \%$ remissions induced by placebo therapy. More than $1000 \mathrm{mg}$ topical 5-ASA do not show a further benefit ${ }^{[11]}$. Topical $5-A S A$ is clearly more potent in inducing remission than topical steroids $^{[14]}$ which are thus second line therapy for patients who are intolerant to topical 5ASA therapy (which is rare). If symptoms persist despite adequate topical monotherapy with 5-ASA, topical agents should first be combined (topical steroids and 5-ASA) before switching to a combination with oral therapy ${ }^{[15]}$.

Left sided colitis should be treated with foam preparations or liquid enemas with an initial dose of at least $2 \mathrm{~g} 5-A S A^{[16]}$. Topical formulations available in Europe are summarized in Table 1. In Switzerland, topical 5-ASA is available as Asacol® liquid enemas $(2 \mathrm{~g}$ and $4 \mathrm{~g} 5$-ASA in a volume of $50 \mathrm{ml}$ and $100 \mathrm{ml}$, respectively), Salofalk $\AA$ liquid enemas ( $2 \mathrm{~g}$ and $4 \mathrm{~g} 5$-ASA in a volume of $30 \mathrm{ml}$ and $60 \mathrm{ml}$, respectively), or Salofalk® foam (1 5 -ASA in a volume of $30 \mathrm{ml}$ ). If symptoms persist despite adequate topical 
monotherapy, topical therapy should first be combined (topical steroids and 5-ASA) ${ }^{[15]}$. In Switzerland, only budesonide is available as active drug in steroid-containing enemas (Entocort@ liquid enema with $2.3 \mathrm{mg}$ budesonide in a volume of $115 \mathrm{ml}$, Budenofalk® rectal foam with $2 \mathrm{mg}$ budesonide in a volume of $30 \mathrm{ml}$ ). If this does not induce remission, oral 5ASA should be added to topical therapies ${ }^{[16]}$ which will further increase the chance of inducing remission. Under these conditions, topical therapies should not be stopped as frequently seen in daily practice. Even in patients that complain about discomfort, topical therapy can be optimized. In moderate left sided UC, it may be advisable to combine oral and topical aminosalicyates from the beginning. The combination of oral and topical 5-ASA is clearly more effective (88\%) as compared to $4 \mathrm{~g}$ of rectal aminosalicyates (54\%) and $2.4 \mathrm{~g}$ oral $5-\mathrm{ASA}^{[16]}$. Indeed, current ECCO guidelines recommend to treat mild to moderate left-sided UC initially with topical and oral 5-ASA ${ }^{[7]}$.

In case of extensive colitis, the treatment strategy is very similar to left-sided colitis. The combination of oral and topical 5-ASA therapy should be explored as the topical therapy may especially reduce the inflammation at the location which is mainly responsible for the patient's complaints of urgency: the rectum. Indeed, the combination of topical 5-ASA with more than $2 \mathrm{~g}$ of oral 5 -ASA has been shown to be substantially more potent to induce remission in extensive colitis than oral-only 5-ASA therapy ${ }^{[17]}$ which induces remission in a significantly lower proportion of patients. Thus, topical 5-ASA also adds a clear benefit for the treatment of extensive colitis. Effectiveness of topical therapies should be evaluated after two weeks. However, if a combination of oral and topical 5-ASA is not sufficient for mild or moderately active UC, oral/systemic steroid treatment is certainly justified. In extensive colitis, the threshold for using systemic steroids should be lower than in leftsided colitis ${ }^{[7]}$.

Severe UC needs to be treated by intravenous steroids as first line therapy. The use of topical treatment has not been studied in severe UC, but topical application (budesonide or 5-ASA) may be considered appropriate in addition to intravenous studies if the patient is able to retain the rectal therapy for at least $20 \mathrm{~min}^{[7]}$. Some experts, however, state that topical therapies should be avoided in case of severe UC since they will not be tolerated. In our daily practice this is the case in some but certainly not all patients with severe colitis. 


\section{Maintenance of remission by topical therapy}

As for induction of remission, aminosalicylates are the mainstay of therapy for the maintenance of remission in patients with UC. Topical 5-ASA is effective for proctitis and left-sided colitis ${ }^{[7,13]}$, and is possibly even more effective than oral $5-A S A{ }^{[7]}$. Clinical trials with rectal 5-ASA preparations for maintenance of remission have been performed with various 5-ASA formulations and dosages per day, week or month, respectively ${ }^{[7]}$. Based on the data available, it can be concluded that in most patients, topical therapy is not necessary on a daily basis but can be applied less frequently as for example during 7 days per month ${ }^{[18]}$ or 2-3 times per week ${ }^{[19]}$. A clear dose-response relationship with topical 5ASA for maintaining remission in distal UC has not been proven ${ }^{[7]}$. Probably $1 \mathrm{~g}$ or less of topically applied 5-ASA is sufficient to relieve inflammation in distal $U^{[9]}$. In clinical practice, finding the minimal dosage of 5-ASA for maintenance of remission remains difficult. Nevertheless there should be no "one-fits-all" approach with respect to maintenance of remission for topical 5-ASA preparations. Predictive factors need to be taken into account, such as severity and frequency of flares before the current remission. If topical therapy is not working sufficiently, combined oral and topical therapy should be considered .

\section{Can mucosal healing be achieved by "only" topical therapies?}

Many experts in the field advocate that mucosal healing should be achieved to gain an optimal prognostic benefit in IBD, irrespective of treatment used ${ }^{[20]}$. According to a recent meta-analysis including data from 2513 patients treated with rectal 5-ASA, mucosal healing can be achieved in about $50 \%$ of UC patients treated with $5-A_{S A}{ }^{[21]}$. There was no evidence in this meta-analysis that the rate of mucosal healing is different between 5-ASA foams and enemas ${ }^{[21]}$. There is further evidence for the effectiveness in inducing mucosal healing by topical 5-ASA as summarized by Sandborn et al. ${ }^{[22]}$ in a recently published post hoc analysis. We must conclude from these results that mucosal healing is possible when "only" rectal 5-ASA therapies are used in distal colitis. Besides mucosal healing is no argument for an aggressive prescription of anti-TNF antibodies which give no guarantee for mucosal healing. In ACT2, about 50\% achieved mucosal healing under infliximab 
treatment ${ }^{[20]}$. Of course, one has to be aware that anti-TNFs are usually given for moderate to severe UC and that these data are no head-to-head comparison.

\section{Side effects of topical therapy}

Topical therapies may have disturbing side effects including leakage, problems with retention and bloating ${ }^{[11]}$. Serious complications such as rectal perforation are only described on the level of case reports ${ }^{[23]}$ and can be assumed to be absolute rarities. Systemic drug-related side effects are rare. Topically applied budesonide (as well as orally administered budesonide) has a very low bioavailability of only $10-15 \%{ }^{[24]}$ and therefore does not show side effects such as cushingoid features or a measurable suppression of basal cortisol levels in the vast majority of patients ${ }^{[25,26]}$. In contrast those side effects occur very frequently with conventional systemic steroids ${ }^{[27]}$.

Topically applied 5-ASA does not have relevant systemic side effects. Idiosyncratic side effects such as interstitial nephritis, myocarditis or pancreatitis are very rare even when oral and systemic forms of 5-ASA are used, without a proven relationship between duration or cumulative dose and the risk of renal disease ${ }^{[28,29]}$. We are not aware of published cases of interstitial nephritis induced by topical 5-ASA therapies. However, there is one case report on a 5-ASA induced acute pancreatitis after the use of 5-ASA suppositories $^{[30]}$. Besides one case report of a 5-ASA enema-induced relapse of acute pancreatits in a patient who already had had a 5-ASA induced acute pancreatitis after oral intake of 5-ASA has been published ${ }^{[31]}$. This higlights that re-exposition with topical 5-ASA in case of pancreatitis, myocarditis, epicarditis or interstitial nephritis as well as other forms of hypersensitivity reactions to 5-ASA requires a very careful risk/benefit analysis.

\section{Adherence to topical therapy}

As relevant for other therapies, acceptance of and compliance with medication is crucial for the success of topical therapy in UC patients. Non-adherence in patients with IBD can be as high as $60 \%{ }^{[32]}$. In a study on medication non-adherence in patients with 5-ASA for maintenance of remission, the vast majority of patients with a relapse of UC were nonadherent $^{[32]}$. Studies have shown that adherence is worse in maintenance therapies $(50 \%)$ 
than in short-term IBD therapy ${ }^{[32,33]}$. However, most patients with non-adherence simply forget to take their medication (as they do very well during remission) ${ }^{[34]}$.

Despite problems with compliance and the fact that most patients (80\%) prefer oral treatment alone ${ }^{[35]}$, it is important to note that most UC patients are willing to use topical therapies $^{[36,37]}$. However, effectiveness of topical therapy is much less likely if it induces too much urgency ${ }^{[37-39]}$. A Spanish study has shown that 5-ASA suppositories are well tolerated and are considered comfortable for treatment of at least one year ${ }^{[5]}$. For enemas, it seems that urgency is associated with a higher volume applied. Thus, most patients prefer foam preparations with less volume applied compared to liquid enema formulations $^{[40,41]}$, although a Cochrane review in 2010 summarized conflicting experience in clinical trials ${ }^{[12]}$. The urgency induced by topical therapies can be explained by the fact that the rectal compliance is clearly reduced in patients with active $U C^{[42-44]}$. We advise to take loperamide $2 \mathrm{mg} 20$ to 30 minutes before applying the enema to reduce urgency, although there is no evidence from clinical studies in UC for this approach. However, in a trial using loperamide in obese patients during orlistat treatment with loose stools as a side effect of orlistat treatment, loperamide had at least some effect on anorectal sphincter function $^{[45]}$, but no effect on rectal capacity or compliance. Furthermore, we advise to lay down in a left sided or prone position after applying topical therapy. There are no studies on how long topical therapy should be retained to be maximally effective. However, even if part of the topical therapy is evacuated, it can be assumed that a relevant part of the drug will adhere to the mucosa ${ }^{[9]}$. Thus, patients should be motivated to try topical therapies even if they cannot be retained for a long time.

\section{Doctor's adherence to guidelines and evidence}

A successful topical therapy not only necessitates patient's adherence but also doctor's adherence to evidence and guidelines. In an interesting survey among Spanish gastroenterologists, only $12-17 \%$ of gastroenterologists consider topical 5-ASA as therapy of choice for distal colitis ${ }^{[46]}$. Only $31 \%$ of gastroenterologists use the combination of oral and topical 5-ASA for extensive mild to moderate UC.

Furthermore, despite evidence that topical 5-ASA is more potent in reducing remission than topical steroids ${ }^{[14]}, 31-47 \%$ of gastroenterologists think that rectal steroid are as 
effective as topical 5-ASA ${ }^{[46]}$. In an analysis of 12 consecutive patients with UC, Reddy and coworkers found that $75 \%$ of patients with left sided UC did not have a topical therapy ${ }^{[47]}$.

\section{New or rare indications and strategies for topical therapies}

In patients with Crohn's proctitis or left sided colitis, one could argue that topical steroids or 5-ASA might be useful. However, it is important to note that Crohn's disease is characterized by a transmural inflammation which may be more difficult to cure by a topical application of steroids. Currently, there are no studies available on the effect of topical therapies with 5-ASA or steroids in Crohn's disease, despite an extensive literature research. Furthermore, it must be kept in mind there is as well no evidence for oral 5-ASA in Crohn's colitis. Thus, topical therapies cannot be recommended for Crohn's proctitis or left-sided Crohn's colitis.

Besides topical therapies with 5-ASA and steroids, some small studies are available with conflicting results on new topical therapies in UC. The most promising alternative topical therapies include the use of probiotics and fecal transplantation, tacrolimus and eventually Alicaforsen. Several other therapeutic strategies have been reviewed by Lawrance ${ }^{[48]}$ and are only mentioned briefly in this review.

- Probiotics: There is good evidence for $E$. coli Nissle in maintenance of remission in UC. E. coli Nissle was consecutively studied as a topical preparation in a double-blind study with 90 patients with moderate distal UC. Liquid enemas containing 10exp8 $\mathrm{EcN} / \mathrm{ml}$ were compared to placebo enemas during a treatment period of 2 weeks. A positive effect could only be demonstrated in the per protocol (PP) analysis, but not in the intention-to-treat-analysis (ITT) (PP: $p=0.0446$, ITT: $p=0.4430)^{[49]}$.

- Fecal transplantation: Given the complexity of the fecal microbiota, it seems reasonable that the approach of fecal transplantation will be more effective than using only a single probiotic strain. Fecal transplantation has mainly been done for treatment of recurrent Clostridium difficile infection, but also in patients with therapy refractory 
UC. More than 20 years ago, the first case of fecal transplantation in UC was published ${ }^{[50]}$. Since then, there have been various case reports showing that fecal transplantation (having various other names such as "stool transplant", "fecal transfer", "fecal microbiota transplantation") can induce remission in UC patients ${ }^{[51]}$. In Crohn's disease, a pilot study showed no clinical or endoscopic efficacy of fecal transplantation in 4 patients ${ }^{[52]}$. Currently, at least three clinical trials are ongoing to study the efficacy of fecal transplantation in UC:

- NCT01560819 in the United States is a phase I pilot study in 10 pediatric UC and CD patients aged 7-12 years. Patients will receive 5 sessions of fecal transplantation by enema with faeces from a donor chosen by the family. - NCT01545908 in Canada is a phase II study for the induction of remission in active UC and aims at enrolling 130 patients. The active arm will be a fecal transplatation from a non-related donor, and the placebo enema will be a saline enema. - NTR2862 in the Netherlands ("turn trial") is a placebo-controlled trial in adults aged 18 years or older and aims at enrolling 40 patients. The active arm will be a fecal transplantation from no further specified healthy donor by duodenal-tube infusion, the placebo arm will receive their own faeces.

Tacrolimus: Tacrolimus is a strong immunosuppressant which is able to induce and maintain remission in severely active UC. However, high serum levels are necessary to induce remission, which predisposes to drug side effects such as tremor, headache, or renal insufficiency. Interestingly, open label studies with (not commercially available) topical tacrolimus preparations were able to induce remission in left-sided UC at a low dose of $1.8-4 \mathrm{mg}$ (either as suppositories, enemas or ointments) and without leading to high serum levels of tacrolimus as seen during oral intake ${ }^{[53,54]}$. There were no relevant side effects observed. Thirteen of 19 patients in one study showed a clinical improvement of disease activity after 4 weeks of local tacrolimus treatment. The other study reported clinical remission in 6 of 8 patients. These results are promising, but a commercially available topical tacrolimus preparation would be needed to allow a wide-spread use of this strategy in left-sided colitis.

- Alicaforsen: In an open-label study with nightly rectal enemas of alicaforsen which is an antisense oligodeoxynucleotide against intercellular adhesion molecule 1 (ICAM-1) mRNA, 33\% of patients reached remission at the end of the 6 week study period ${ }^{[55]}$. 
Similarly, 7 of 12 patients using alicaforsen with chronic unremitting pouchitis reached remission ${ }^{[56]}$. These results look very promising, but alicaforsen is still only a candidate as orphan drug in Europe. Further randomized trials are clearly warranted.

Several small and sometimes quite old studies analyzed various other therapeutic approaches, with sometimes promising but no convincing results allowing their use in clinical practice. ${ }^{[48]}$

- $\quad$ Liquid enemas with ciclosporin A initially looked promising in open-label studies ${ }^{[57]}$, but were not shown to be active in placebo-controlled randomized trials ${ }^{[58]}$.

- Similarly, Butyrate enemas were promising in open-label studies ${ }^{[59]}$, but not in placebocontrolled randomized trials ${ }^{[60]}$.

- Since impaired epithelial expression of peroxisome proliferator-activated receptor $\chi$ (PPAR $\chi$ ) ligand was described in ulcerative colitis, a topically administered

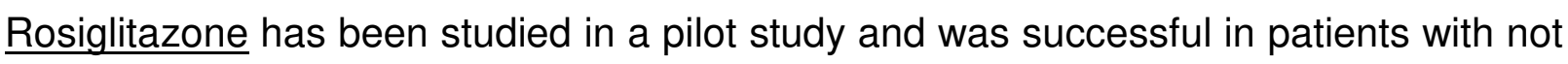
previously treated IBD patients ${ }^{[61]}$. However, rosiglitazone has been withdrawn in 2010 due to cardiovascular side effects. We are not aware of ongoing or planned studies with other PPAR Gamma ligands in IBD.

- $\quad$ Nicotine enemas containing $6 \mathrm{mg}$ of nicotine have been studied in a large randomized double-blind study including 104 patients with active $U^{[62]}$. However, 6mg of topical nicotine were not found to be efficacious for active UC.

- $\quad$ Arsenic suppositories (250mg b.d. for 4 weeks) have been studied in only one small study with 10 patients $^{[63]}$. In 9 of 10 patients, symptoms and endoscopic signs of proctitis resolved within 2 weeks, but 6 of 10 patients showed a relevant systemic arsenic absorption. Currently, arsenic suppositories are infrequently used.

- Further therapeutic strategies include the use of lidocaine enemas, Ecabet enemas, Epidermal growth factor enemas, remapimide enemas and thromboxane enemas ${ }^{[48]}$.

\section{Conclusions}

Topical therapies are effective and feasible in proctitis and left-sided colitis for both induction and maintenance of remission. If topical therapies are not sufficiently efficacous in left-sided UC, they should be combined with and not replaced by oral 5-ASA. Topical 
budesonide should be used if topical 5-ASA is not effective or in case of intolerance to topical 5-ASA which is rare. In extensive colitis, oral and topical 5-ASA should be combined. Only in severe UC, topical therapies may be omitted because they lack sufficient efficacy and may not be tolerated by patients. There is insufficient evidence for the efficacy of topical therapies in Crohn's disease including Crohn's colitis. Some new topical therapeutics have recently been or are currently studied for the treatment of UC.

\section{Acknowledgements}

The authors thank Dr. Sarah Schneeberger, pharmacist at the Kantonsapotheke Zürich, for her help in creating Table 1 by using pharmavista. Dr. P. Frei thanks members of the young clinicians programme at the UEGW 2009 who helped to collect data on topical therapy in their home countries.

Grant support: This research was supported by grants from the Swiss National Science Foundation (SNF) to SRV (Grant No 320000-114009/3 and 32473B_135694/1), by the Zurich Center for Integrative Human Physiology (ZIHP) of the University of Zurich, and the Swiss IBD Cohort (Grant No. 3347CO-108792).

\section{Referenzen}

1 Bresci G, Parisi G, Gambardella L, Banti S, Bertoni M, Rindi G, Capria A. Evaluation of clinical patterns in ulcerative colitis: a long-term follow-up. Int J Clin Pharmacol Res 1997; 17(1): 17-22 [PMID: 9403349]

2 Lakatos PL, Lakatos L. Ulcerative proctitis: a review of pharmacotherapy and management. Expert Opin Pharmacother 2008; 9(5): 741-749 [PMID: 18345952 DOI: 10.1517/14656566.9.5.741]

3 Rogler G. Medical management of ulcerative colitis. Dig Dis 2009; 27(4): 542-549 [PMID: 19897972 DOI: 000233295 [pii] 
10.1159/000233295]

4 Brunner M, Vogelsang H, Greinwald R, Kletter K, Kvaternik H, Schrolnberger C, Eichler HG, Brunner H, Dudczak R, Muller M. Colonic spread and serum pharmacokinetics of budesonide foam in patients with mildly to moderately active ulcerative colitis. Aliment Pharmacol Ther 2005; 22(5): 463-470 [PMID: 16128685 DOI: APT2571 [pii] 10.1111/j.1365-2036.2005.02571.x]

5 Casellas F, Vaquero E, Armengol JR, Malagelada JR. Practicality of 5-aminosalicylic suppositories for long-term treatment of inactive distal ulcerative colitis. Hepatogastroenterology 1999; 46(28): 2343-2346 [PMID: 10521994]

6 Campieri M, Corbelli C, Gionchetti P, Brignola C, Belluzzi A, Di Febo G, Zagni P, Brunetti G, Miglioli M, Barbara L. Spread and distribution of 5-ASA colonic foam and 5ASA enema in patients with ulcerative colitis. Dig Dis Sci 1992; 37(12): 1890-1897 [PMID: 1473437]

7 Travis SP, Stange EF, Lemann M, Oresland T, Bemelman WA, Chowers $\mathrm{Y}$, Colombel JF, D'Haens G, Ghosh S, Marteau P, Kruis W, Mortensen NJ, Penninckx F, Gassull M. European evidence-based Consensus on the management of ulcerative colitis: Current management. J Crohns Colitis 2008; 2(1): 24-62 [PMID: 21172195 DOI: S18739946(07)00076-1 [pii]

10.1016/j.crohns.2007.11.002]

8 Eliakim R, Tulassay Z, Kupcinskas L, Adamonis K, Pokrotnieks J, Bar-Meir S, Lavy A, Mueller R, Greinwald R, Chermesh I, Gross V. Clinical trial: randomized-controlled clinical study comparing the efficacy and safety of a low-volume vs. a high-volume mesalazine foam in active distal ulcerative colitis. Aliment Pharmacol Ther 2007; 26(9): 1237-1249 [PMID: 17944738 DOI: APT3468 [pii]

10.1111/j.1365-2036.2007.03468.x]

9 Harris MS, Lichtenstein GR. Review article: delivery and efficacy of topical 5aminosalicylic acid (mesalazine) therapy in the treatment of ulcerative colitis. Aliment Pharmacol Ther 2011; 33(9): 996-1009 [PMID: 21385194 DOI: 10.1111/j.13652036.2011.04619.x]

10 D'Arienzo A, Panarese A, D'Armiento FP, Lancia C, Quattrone P, Giannattasio F, Boscaino A, Mazzacca G. 5-Aminosalicylic acid suppositories in the maintenance of 
remission in idiopathic proctitis or proctosigmoiditis: a double-blind placebo-controlled clinical trial. Am J Gastroenterol 1990; 85(9): 1079-1082 [PMID: 2202199]

11 Gionchetti P, Rizzello F, Venturi A, Brignola C, Ferretti M, Peruzzo S, Campieri M. Comparison of mesalazine suppositories in proctitis and distal proctosigmoiditis. Aliment Pharmacol Ther 1997; 11(6): 1053-1057 [PMID: 9663829]

12 Marshall JK, Thabane M, Steinhart AH, Newman JR, Anand A, Irvine EJ. Rectal 5aminosalicylic acid for induction of remission in ulcerative colitis. Cochrane Database Syst Rev 2010(1): CD004115 [PMID: 20091560 DOI: 10.1002/14651858.CD004115.pub2]

13 Marshall JK, Irvine EJ. Rectal aminosalicylate therapy for distal ulcerative colitis: a meta-analysis. Aliment Pharmacol Ther 1995; 9(3): 293-300 [PMID: 7654892]

14 Marshall JK, Irvine EJ. Rectal corticosteroids versus alternative treatments in ulcerative colitis: a meta-analysis. Gut 1997; 40(6): 775-781 [PMID: 9245932 PMCID: 1027203]

15 Mulder CJ, Fockens P, Meijer JW, van der Heide H, Wiltink EH, Tytgat GN. Beclomethasone dipropionate (3 $\mathrm{mg})$ versus 5-aminosalicylic acid $(2 \mathrm{~g})$ versus the combination of both $(3 \mathrm{mg} / 2 \mathrm{~g})$ as retention enemas in active ulcerative proctitis. Eur $J$ Gastroenterol Hepatol 1996; 8(6): 549-553 [PMID: 8823568]

16 Safdi M, DeMicco M, Sninsky C, Banks P, Wruble L, Deren J, Koval G, Nichols T, Targan S, Fleishman C, Wiita B. A double-blind comparison of oral versus rectal mesalamine versus combination therapy in the treatment of distal ulcerative colitis. Am J Gastroenterol 1997; 92(10): 1867-1871 [PMID: 9382054]

17 Marteau P, Probert CS, Lindgren S, Gassul M, Tan TG, Dignass A, Befrits R, Midhagen G, Rademaker J, Foldager M. Combined oral and enema treatment with Pentasa (mesalazine) is superior to oral therapy alone in patients with extensive mild/moderate active ulcerative colitis: a randomised, double blind, placebo controlled study. Gut 2005; 54(7): 960-965 [PMID: 15951542 PMCID: 1774619 DOI: 54/7/960 [pii] 10.1136/gut.2004.060103]

18 d'Albasio G, Trallori G, Ghetti A, Milla M, Nucci A, Pacini F, Morettini A. Intermittent therapy with high-dose 5-aminosalicylic acid enemas for maintaining remission in ulcerative proctosigmoiditis. Dis Colon Rectum 1990; 33(5): 394-397 [PMID: 1970284] 19 Marteau P, Crand J, Foucault M, Rambaud JC. Use of mesalazine slow release suppositories $1 \mathrm{~g}$ three times per week to maintain remission of ulcerative proctitis: a 
randomised double blind placebo controlled multicentre study. Gut 1998; 42(2): 195-199 [PMID: 9536943 PMCID: 1727004]

20 Lichtenstein GR, Rutgeerts P. Importance of mucosal healing in ulcerative colitis. Inflamm Bowel Dis 2010; 16(2): 338-346 [PMID: 19637362 DOI: 10.1002/ibd.20997] 21 Romkens TE, Kampschreur MT, Drenth JP, van Oijen MG, de Jong DJ. High mucosal healing rates in 5-ASA-treated ulcerative colitis patients: Results of a metaanalysis of clinical trials. Inflamm Bowel Dis 2012 [PMID: 22419617 DOI: 10.1002/ibd.22939]

22 Sandborn WJ, Hanauer S, Lichtenstein GR, Safdi M, Edeline M, Scott Harris M. Early symptomatic response and mucosal healing with mesalazine rectal suspension therapy in active distal ulcerative colitis--additional results from two controlled studies. Aliment Pharmacol Ther 2011; 34(7): 747-756 [PMID: 21848857 DOI: 10.1111/j.13652036.2011.04800.x]

23 Tanswell IJ, Irfan K, Kossakowski T, Townson G. Rectal perforation in ulcerative colitis: complication of an enema tip. Gastrointest Endosc 2009; 69(2): 344; discussion 344 [PMID: 19185695 DOI: S0016-5107(08)02433-4 [pii]

10.1016/j.gie.2008.08.023]

24 Klotz U, Schwab M. Topical delivery of therapeutic agents in the treatment of inflammatory bowel disease. Adv Drug Deliv Rev 2005; 57(2): 267-279 [PMID: 15555742 DOI: S0169-409X(04)00197-8 [pii]

10.1016/j.addr.2004.08.007]

25 Danielsson A, Lofberg R, Persson T, Salde L, Schioler R, Suhr O, Willen R. A steroid enema, budesonide, lacking systemic effects for the treatment of distal ulcerative colitis or proctitis. Scand J Gastroenterol 1992; 27(1): 9-12 [PMID: 1736348]

26 Hanauer SB, Robinson M, Pruitt R, Lazenby AJ, Persson T, Nilsson LG, WaltonBowen K, Haskell LP, Levine JG. Budesonide enema for the treatment of active, distal ulcerative colitis and proctitis: a dose-ranging study. U.S. Budesonide enema study group. Gastroenterology 1998; 115(3): 525-532 [PMID: 9721148 DOI: S0016508598002273 [pii]] 27 Bili H, Algayres JP, Revel F, Coutant G, Daly JP. [Acute adrenal insufficiency after stopping prolonged corticotherapy with betnesol enemas for ulcerative colitis]. Gastroenterol Clin Biol 1998; 22(12): 1113-1114 [PMID: 10051992 DOI: 64700 [pii]] 
28 Gisbert JP, Gonzalez-Lama Y, Mate J. 5-Aminosalicylates and renal function in inflammatory bowel disease: a systematic review. Inflamm Bowel Dis 2007; 13(5): 629-638 [PMID: 17243140 DOI: 10.1002/ibd.20099]

29 Moss AC, Peppercorn MA. The risks and the benefits of mesalazine as a treatment for ulcerative colitis. Expert Opin Drug Saf 2007; 6(2): 99-107 [PMID: 17367256 DOI: 10.1517/14740338.6.2.99]

$30 \mathrm{Kim} \mathrm{KH}$, Kim TN, Jang BI. [A case of acute pancreatitis caused by 5-aminosalicylic acid suppositories in a patient with ulcerative colitis]. Korean J Gastroenterol 2007; 50(6): 379-383 [PMID: 18159175 DOI: 200712256 [pii]]

31 Schworer H, Ramadori G. [Acute pancreatitis--adverse effect of 5-aminosalicylic acid (mesalazine) in various galenic dosage forms]. Dtsch Med Wochenschr 2000; 125(44): 1328-1330 [PMID: 11109415 DOI: 10.1055/s-2000-8072]

32 Kane SV, Cohen RD, Aikens JE, Hanauer SB. Prevalence of nonadherence with maintenance mesalamine in quiescent ulcerative colitis. Am J Gastroenterol 2001; 96(10): 2929-2933 [PMID: 11693328 DOI: S0002-9270(01)03245-2 [pii]

10.1111/j.1572-0241.2001.04683.x]

33 Sewitch MJ, Abrahamowicz M, Barkun A, Bitton A, Wild GE, Cohen A, Dobkin PL. Patient nonadherence to medication in inflammatory bowel disease. Am $J$ Gastroenterol 2003; 98(7): 1535-1544 [PMID: 12873575 DOI: S0002927003003046 [pii]

10.1111/j.1572-0241.2003.07522.x]

34 Kane SV, Huo D, Aikens J, Hanauer SB. Medication nonadherence and the outcomes of patients with quiescent ulcerative colitis. Am J Med 2003; 114: 39-43

35 Moody GA, Eaden JA, Helyes Z, Mayberry JF. Oral or rectal administration of drugs in IBD? Aliment Pharmacol Ther 1997; 11(5): 999-1000 [PMID: 9354213]

36 Kane SV. Systematic review: adherence issues in the treatment of ulcerative colitis. Aliment Pharmacol Ther 2006; 23(5): 577-585 [PMID: 16480396 DOI: APT2809 [pii] 10.1111/j.1365-2036.2006.02809.x]

37 Kane SV, Brixner D, Rubin DT, Sewitch MJ. The challenge of compliance and persistence: focus on ulcerative colitis. J Manag Care Pharm 2008; 14(1 Suppl A): s2-12; quiz s13-15 [PMID: 18240888 DOI: 2008(14)1: 2-15 [pii]] 
38 Fernandez-Becker NQ, Moss AC. Improving delivery of aminosalicylates in ulcerative colitis: effect on patient outcomes. Drugs 2008; 68(8): 1089-1103 [PMID: 18484800 DOI: 6886 [pii]]

39 Prantera C, Rizzi M. 5-ASA in ulcerative colitis: improving treatment compliance. World J Gastroenterol 2009; 15(35): 4353-4355 [PMID: 19764084 PMCID: 2747053]

40 Cortot A, Maetz D, Degoutte E, Delette O, Meunier P, Tan G, Cazals JB, Dewit O, Hebuterne X, Beorchia S, Grunberg B, Leprince E, D'Haens G, Forestier S, Idier I, Lemann M. Mesalamine foam enema versus mesalamine liquid enema in active left-sided ulcerative colitis. Am J Gastroenterol 2008; 103(12): 3106-3114 [PMID: 19086960 DOI: AJG2152 [pii]

10.1111/j.1572-0241.2008.02152.x]

41 Gross V, Bar-Meir S, Lavy A, Mickisch O, Tulassay Z, Pronai L, Kupcinskas L, Kiudelis G, Pokrotnieks J, Kovacs A, Faszczyk M, Razbadauskas A, Margus B, Stolte M, Muller R, Greinwald R. Budesonide foam versus budesonide enema in active ulcerative proctitis and proctosigmoiditis. Aliment Pharmacol Ther 2006; 23(2): 303-312 [PMID: 16393311 DOI: APT2743 [pii]

10.1111/j.1365-2036.2006.02743.x]

42 Loening-Baucke V, Metcalf AM, Shirazi S. Anorectal manometry in active and quiescent ulcerative colitis. Am J Gastroenterol 1989; 84(8): 892-897 [PMID: 2756980]

43 Rao SS, Read NW, Davison PA, Bannister JJ, Holdsworth CD. Anorectal sensitivity and responses to rectal distention in patients with ulcerative colitis. Gastroenterology 1987; 93(6): 1270-1275 [PMID: 3678745 DOI: S0016508587003457 [pii]]

44 Suzuki H, Fujioka M. Rectal pressure and rectal compliance in ulcerative colitis. Jpn J Surg 1982; 12(1): 79-81 [PMID: 7069952]

45 Fox M, Stutz B, Menne D, Fried M, Schwizer W, Thumshirn M. The effects of loperamide on continence problems and anorectal function in obese subjects taking orlistat. Dig Dis Sci 2005; 50(9): 1576-1583 [PMID: 16133954 DOI: 10.1007/s10620-0052900-6]

46 Gisbert JP, Gomollon F, Hinojosa J, Lopez San Roman A. Adherence of gastroenterologists to European Crohn's and Colitis Organisation consensus on ulcerative colitis: a real-life survey in Spain. J Crohns Colitis 2010; 4(5): 567-574 [PMID: 21122561 DOI: S1873-9946(10)00091-7 [pii] 
10.1016/j.crohns.2010.06.001]

47 Reddy SI, Friedman S, Telford JJ, Strate L, Ookubo R, Banks PA. Are patients with inflammatory bowel disease receiving optimal care? Am J Gastroenterol 2005; 100(6): 1357-1361 [PMID: 15929770 DOI: AJG40849 [pii]

10.1111/j.1572-0241.2005.40849.x]

48 Lawrance IC. Novel topical therapies for distal colitis. World J Gastrointest Pharmacol Ther 2010; 1(5): 87-93 [PMID: 21577301 PMCID: 3091152 DOI: 10.4292/wjgpt.v1.i5.87]

49 Matthes H, Krummenerl T, Giensch M, Wolff C, Schulze J. Clinical trial: probiotic treatment of acute distal ulcerative colitis with rectally administered Escherichia coli Nissle 1917 (EcN). BMC Complement Altern Med 2010; 10: 13 [PMID: 20398311 PMCID: 2861635 DOI: 1472-6882-10-13 [pii]

10.1186/1472-6882-10-13]

50 Bennet JD, Brinkman M. Treatment of ulcerative colitis by implantation of normal colonic flora. Lancet 1989; 1(8630): 164 [PMID: 2563083]

51 Borody TJ, Campbell J. Fecal microbiota transplantation: current status and future directions. Expert Rev Gastroenterol Hepatol 2011; 5(6): 653-655 [PMID: 22017691 DOI: 10.1586/egh.11.71]

52 Vermeire S, Joossens M, Verbeke K, Hildebrand F, Machiels K, Van den Broeck K, Van Assche G, P.J. R, Raes J. Pilot Study on the Safety and Efficacy of Faecal Microbiota Transplantation in

Refractory Crohn's Disease. Gastroenterology 2012; 1425, Supplement 1(5, Supplement 1): S-360

53 Lawrance IC, Copeland TS. Rectal tacrolimus in the treatment of resistant ulcerative proctitis. Aliment Pharmacol Ther 2008; 28(10): 1214-1220 [PMID: 18761706 DOI: APT3841 [pii]

10.1111/j.1365-2036.2008.03841.x]

54 van Dieren JM, van Bodegraven AA, Kuipers EJ, Bakker EN, Poen AC, van Dekken $\mathrm{H}$, Nieuwenhuis EE, van der Woude CJ. Local application of tacrolimus in distal colitis: feasible and safe. Inflamm Bowel Dis 2009; 15(2): 193-198 [PMID: 18825773 DOI: 10.1002/ibd.20644]

55 Miner PB, Jr., Geary RS, Matson J, Chuang E, Xia S, Baker BF, Wedel MK. Bioavailability and therapeutic activity of alicaforsen (ISIS 2302) administered as a rectal 
retention enema to subjects with active ulcerative colitis. Aliment Pharmacol Ther 2006; 23(10): 1427-1434 [PMID: 16669957 DOI: APT2909 [pii]

10.1111/j.1365-2036.2006.02909.x]

56 Miner P, Wedel M, Bane B, Bradley J. An enema formulation of alicaforsen, an antisense inhibitor of intercellular adhesion molecule-1, in the treatment of chronic, unremitting pouchitis. Aliment Pharmacol Ther 2004; 19(3): 281-286 [PMID: 14984374 DOI: 1863 [pii]]

57 Sandborn WJ, Tremaine WJ, Schroeder KW, Steiner BL, Batts KP, Lawson GM. Cyclosporine enemas for treatment-resistant, mildly to moderately active, left-sided ulcerative colitis. Am J Gastroenterol 1993; 88(5): 640-645 [PMID: 8480724]

58 Sandborn WJ, Tremaine WJ, Schroeder KW, Batts KP, Lawson GM, Steiner BL, Harrison JM, Zinsmeister AR. A placebo-controlled trial of cyclosporine enemas for mildly to moderately active left-sided ulcerative colitis. Gastroenterology 1994; 106(6): 1429-1435 [PMID: 8194687 DOI: S0016508594001599 [pii]]

59 Scheppach W, Sommer H, Kirchner T, Paganelli GM, Bartram P, Christl S, Richter F, Dusel G, Kasper $\mathrm{H}$. Effect of butyrate enemas on the colonic mucosa in distal ulcerative colitis. Gastroenterology 1992; 103(1): 51-56 [PMID: 1612357 DOI: S0016508592003044 [pii]]

60 Scheppach W. Treatment of distal ulcerative colitis with short-chain fatty acid enemas. A placebo-controlled trial. German-Austrian SCFA Study Group. Dig Dis Sci 1996; 41(11): 2254-2259 [PMID: 8943981]

61 Pedersen G, Brynskov J. Topical rosiglitazone treatment improves ulcerative colitis

by restoring peroxisome proliferator-activated receptor-gamma activity. $A m ~ J$ Gastroenterol 2010; 105(7): 1595-1603 [PMID: 20087330 DOI: ajg2009749 [pii]

10.1038/ajg.2009.749]

62 Ingram JR, Thomas GA, Rhodes J, Green JT, Hawkes ND, Swift JL, Srivastava ED, Evans BK, Williams GT, Newcombe RG, Courtney E, Pillai S. A randomized trial of nicotine enemas for active ulcerative colitis. Clin Gastroenterol Hepatol 2005; 3(11): 11071114 [PMID: 16271342 DOI: S1542-3565(05)00849-9 [pii]]

63 Forbes A, Britton TC, House IM, Gazzard BG. Safety and efficacy of acetarsol suppositories in unresponsive proctitis. Aliment Pharmacol Ther 1989; 3(6): 553-556 [PMID: 2518869] 


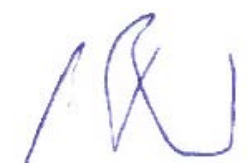

Pascal Frei

Version 2012-07-13 